\title{
C. S. Peirce's Argument for God's Reality: A Pragmatist's View
}

Charles Sanders Peirce, one of America's greatest logicians and perhaps her most original philosopher, founder of the movement called pragmatism, was also a theist. According to his own account he is a theist because he is a pragmatist. Thus, he could write to William James that theism is nothing but "good sound solid strong pragmatism" (8.262).

Nevertheless, religion for Peirce is a topic of "vital importance" and so is a matter more of the heart than of the head. He writes that all sensible talk about religion, morals, and aesthetics "must be common-place, all reasoning about them unsound, and all study of them narrow and sordid" (1.677). When it is a question of great decisions affecting our lives, it is the wise man who knows that sentiment and instinct are sure guides, while reasoning about such matters is out of place since that faculty is a notoriously fallible instrument (1.650-653)

Again, Pierce never seems to tire of telling us that when it is a question of belief, theoretical argumentation has little or no place. Conversely, when it is a question of theoretical or scientific inquiry, there is little or no room for belief. How is it, then, that Peirce presents us with an argument for God's reality? He calls it sometimes the Humble Argument, sometimes the Neglected Argument, and humble though it might be and neglected though it surely has been, it is nonetheless an argument. ${ }^{1}$ The answer to this question

An earlier version of this chapter appeared in The Pappin Festschrft. II. Wisdom and Knowledge: Essays in Honour of Joseph Papin, ed. Joseph Armenti (Villanova: Villanova University Press, 1976), 224-44. 
can only come from a study of the kind of argument it is, and this, of course, is the aim of this essay.

This much can be said now. Peirce's point in those remarks about the relation of a belief to scientific inquiry is that the conviction required to make a theoretical proposition (or at least a proposition capable of theoretical investigation) into an operative principle influencing our conduct is rooted in instinct rather than in scientific inquiry itself. Scientific inquiry, as a form of human conduct, is ultimately rooted in instinct too. Of course, it is possible, even necessary, for a reasonable man to submit beliefs to critical evaluation once he has begun to doubt those beliefs. But this does not take away from the fact that the scientific inquiry which evaluates doubted beliefs itself depends upon other beliefs which are in fact undoubted.

According to Peirce, some beliefs remain undoubted because of the instinctive basis of reason itself. Scientific inquiry itself is a function of a natural disposition or instinct in man-his rationality. In effect, Pierce tries to give a theoretical argument based on the nature of scientific inquiry why instinct is to be trusted as a guide to human conduct and why in the end this trust is reasonable. Truly instinctive beliefs are essentially vague, and insofar as they are vague, they are strictly indubitable. Any attempt to render such beliefs non-vague will fail, in that a residue of the old vague belief not touched by the non-vague formulation will remain. To the extent that some particular formulation of an instinctive belief is definite (non-vague), that formulation is open to doubt and demands critical review. Thus, in Peirce's view, belief in God is instinctive. The formulation of that hypothesis comes naturally and spontaneously to anyone who seriously engages in the activity he calls "musement." Furthermore, critical reflection upon the hypothesis, Pierce contends, shows that although any non-vague formulation of that hypothesis may be doubted as true and accurate, still some residue of the belief remains and some formulations can be shown to be less false than their opposites. In the end the Godhypothesis is supposed by a correct analysis of scientific inquiry. Insofar as the hypothesis remains vague, it is indubitable, and insofar as it is made definite, it is truer (less false) than its opposite.

Of course, we are well ahead of ourselves already. What has been sketched in the preceding paragraph is what we must consider in 
some detail in the rest of this essay. From the list of items involved in Pierce's thought in the matter it is not surprising that in the Hibbert Journal article where he presented his "argument," Peirce could give only a "poor sketch" and a "sort of table of contents" of a complete inquiry into God's reality. I can do little more than follow his example. I will try to pass in review the elements of his outline and comment upon them in the light of his other work and in terms of certain problems that they raise. It is hoped that by throwing some light upon the "Cimmerian darkness" which James found surrounding Pierce"s "flashes of brilliance," 2 this will tempt the reader no longer to "neglect" Peirce's "humble" argument. Perhaps, however, this effort will succeed only in confirming the reader in the opinion that such an argument has only received its just deserts in being neglected. Either way it is hoped that it will be of some use.

\section{DEFINITIONS}

Peirce begins with a glossary of terms (6.452-456). A defense of his usage would require a presentation of his entire categorial scheme and theory of knowledge (according to Peirce a bad translation of Erkenntnislehre). Let us examine these terms which he thinks necessary to an understanding of his argument.

(1) "God": the definable proper name of Ens necessarium, Creator of the three Universes of Experience. In another place (6.494), in answer to the question "Do you believe in the existence of a Supreme Being?" Pierce explains that he prefers the term "God" and that the latter term is the common English word. As the common word it is in one sense understood by everyone and in another sense remains extremely vague. Its vagueness is not reduced by saying that "God" imports "infinity" or "necessity" or any other traditional attribute, because these are equally vague. Now, it is the very vagueness of the term "God" which recommends it as the more appropriate term. We shall see why presently.

(2) "Real": to be real is to have properties sufficient to identify their subject whether or not anyone actually attributes them to it. "Real" is not a synonym for "actual" or "existent." It is a broader term which includes these. Whatever is actual or existent is real, 
but not the converse. The "actual or existent is what is encountered in space and time. It interacts with the spatio-temporal environment" $(6.454,6.495)$. Strictly speaking, therefore, God cannot be said to be actual or to exist, because this would make God simply another spatio-temporal object. God can properly be said only to be real.

In answer to the question cited in paragraph (1) above, Peirce also makes these remarks:

I will also take the liberty of substituting "reality" for "existence." This is perhaps overscrupulosity; but I myself always use exist in its strictest philosophical sense of "react with the other like things in the environment." Of course, in that sense, it would be fetishism to say that God "exists." (6.495)

Perhaps the reader already familiar with Peirce's thought recognizes the peculiar brand of "scholastic realism" which prompts this distinction.

(3) "Experience": a conscious effect produced upon a subject by brute interaction with the environment such that it contributes to the formation of a habit, self-controlled yet so satisfying upon deliberation that it cannot be destroyed by any mere exercise of internal vigor. Such habits are broken or modified only by further brute interactions which come as a shock. All knowledge, Pierce holds, is based on direct experience. This includes knowledge of God. Furthermore, the real and the knowable are co-extensive. There is, then, no such thing as the absolutely incognizable. Consequently, if God is real, $\mathrm{He}$ is knowable, and whatever knowledge of Him we can achieve, vague as it must be, comes through direct experience. It follows, then, that although God cannot be just another object in space and time, His reality is manifested there or not at all $(6.492-493)$ :

as to God, open your eyes-and your heart, which is also a perceptive organ - and you see him. But you may ask, 'Don't you admit there are any delusions?' Yes: I may think a thing is black, and on close examination it may turn out to be bottle-green. But I cannot think a thing is black if there is no such thing to be seen as black. Neither can I think that a certain action is self-sacrificing, if no such thing as self-sacrifice exists, although it may be very rare. It is the nominalists and the nominalists alone, who indulge in such scepticism, which the scientific method utterly condemns. (6.493) 
Peirce once remarked in a letter to James that he held a form of the "ontological argument" (8.262). Presumably the Neglected Argument is supposed to help us open our eyes-and our hearts.

(4) "Universes of Experience": the three constitutive elements of any experience. They are Possibility, Actuality, and Mediation ("connectedness"). These, of course, are an application of the categories of Firstness, Secondness, and Thirdness. The Universe of Possibles comprises all mere Ideas, "those airy nothings" dear to poets and mathematicians, whose reality consists, not in their actually being thought or in their instantiation, but in their capability of either. The Universe of Actuals is that of brute fact and of things whose reality consists in their reaction against brute force. The third universe is made up of "everything whose being consists in active power to establish connection between different objects, especially between objects in different universes" (6.455). Peirce includes here all regularity of nature, mediation, continuity, and representation. This third category is the category of the real and the intelligible par excellence because it is the synthesis of the other two.

(5) "Argument": "any process of thought reasonably tending to produce a definite belief" (6.456). It is to be distinguished from argumentation. Argumentation is an argument proceeding from definitely formulated premises. Argument is a living process of thought; argumentation is the representation of that process in judgments expressed in non-vague terms. No judgment can be non-vague in every respect. If it were, it would be absolutely determinate and so would lose its character as a representation. Arguments are of three types: retroductive, deductive, and inductive (see, for example, 2.266-270). Any of these arguments becomes argumentation when and to the extent that its premises are definitely formulated. Argumentations, then, are to arguments what still shots are to motion pictures-or what position is to motion. There is always more to argument than can be caught in an argumentation. Since, for the purposes of analysis, arguments must be formulated, it would be easy to assume that the only form of argument is argumentation. Peirce thinks that this sort of mistake is one reason why his argument has been neglected:

of all those theologians . . . who, with commendable assiduity, scrape together all the sound reasons they can find or concoct to 
prove the first proposition of theology, few mention this one, and they most briefly. They probably share those current notions of logic which recognize no other Arguments than Argumentations. (6.457)

In particular, Peirce considered the first step in the complete inquiry into God's reality, the retroductive step, to be a form of argument rather than argumentation (6.469). Failure to distinguish argument from argumentation springs from two oversights. The first is failure to take vagueness seriously. Adherents of "those current notions of logic" assumed that vagueness had no place in logic and must be eliminated. This mistake might have been avoided if they had analyzed vagueness (see, for example, 5.446 and 5.505ff.). The second is failure to distinguish lived experience from its representation (see 6.435-439).

\section{General Characteristics of Peirce’s Theism}

Before we proceed to a presentation of the argument, it will be helpful to review Peirce's idea of what sound theism must be like. It must be pragmatic, anthropomorphic, and vague. ${ }^{3}$

(1) "Pragmatic": to be a belief at all, belief in God must make a difference to human conduct. Furthermore, if belief in God is a true belief (and not merely truly believed), God must be a reality that makes a difference to human conduct. Not only must belief or non-belief make a difference, but so also must the reality or non-reality of God. The way in which God is described, the attributes by which we characterize Him, must show Him to be intimately involved in human life. Still, this characterization must be such that it does not make God any less God. According to Peirce, the traditional predicates of natural theology fulfill these requirements.

In a letter to James, Peirce complains that Royce's Absolute "is strictly speaking only God in a Pickwickian sense, that is, in a sense that has no effect" (8.277). God may well be absolute, but if nothing more is said, God is left too abstract and formal to be an object of belief. While such a characterization has the merit of indicating that God is not merely another spatio-temporal object, it does not connect Him with human experience and does not show 
that knowledge of Him arises from experience. Peirce gives God the abstract predicate Ens necessarium but adds that $\mathrm{He}$ is one, personal, transcendent, Creator of the universes of experience, omniscient, omnipotent, infallible, not subject to time, not finite, provident.

(2) "Anthropomorphic": this follows from what has just been said. Peirce refers to anthropomorphism as but another term for pragmatism considered as the analysis of scientific method (8.262). Human reasoning as a development of instinct depends upon conceptions taken from experience. Hence, at bottom, all human conceptions, scientific hypotheses included, are anthropomorphic (5.47, 5.536).

I hold . . . that man is so completely hemmed in by the bounds of his possible experience, his mind is so restricted to being the instrument of his needs, that he cannot, in the least, mean anything which transcends those limits. (5.536)

Thus, God must be known in and through experience (God must be immanent), and yet He must be known as other than any object of experience (God must be transcendent). To say that man cannot go beyond the limits of his possible experience does not and need not prevent him from trying to conceive of "a supreme and indeed transcendent cause or agency of the entire universe." Peirce remarks that it would be like passing a law prohibiting man from jumping over the moon; this would not prevent him from jumping as high as he could. When all is said and done, Peirce opines, man will find no more adequate way of conceiving this "supreme agency" than as "vaguely like a man" (5.536).

To say, therefore, that a conception is one natural to man, which comes to just about the same thing as to say that it is anthropomorphic, is as high a recommendation as one could give to it in the eyes of an Exact Logician. (5.47)

(3) "Vague": vagueness is a form of indeterminateness. Generality is another. A subject is said to be determinate with respect to a character when that character is predicated of it universally and affirmatively (this holds also for the character's complement). In all other respects the subject is indeterminate. A sign is objectively general if it leaves to the interpreter to supply further determina- 
tions. Thus, in the sentence "Man is mortal" the term "man" is objectively general because the answer to the question "Which man?" is "Any one you choose." A sign is vague if it reserves for some other possible sign, and not for the interpreter, the function of completing the determination. Thus, in the sentence "This month a great event will happen," the term "great event" is objectively vague because the answer to the question "Which event?" is not "Any one you like," but rather "Wait and see" (5.447, 5.505). Since there is no term absolutely incapable of logical division (no logical atom), every term is to some degree indeterminate (3.9394). Furthermore, every sign leaves to the utterer some further degree of determination. Its vagueness is removed only by rendering it general. Thus, an affirmative predication covers generally every essential character of the predicate, while a negative predication vaguely denies some essential character (5.447). Since, then, every sign is both vague and general (though not in the same respect), absolute determination and precision cannot be attained (5.477; see also 2.357).

Vagueness and generality may also be distinguished as follows: "Anything is general in so far as the principle of excluded middle does not apply to it" (5.448; see also 5.505). Thus, Peirce observes that a triangle in general is not isosceles, nor equilateral, nor scalene. Anything "is vague in so far as the principle of contradiction does not apply to it" (5.448). Thus, it is false neither that an animal is male nor that an animal is female (5.505).

On Peirce's account, instinctive beliefs are acritically indubitable, and acritically indubitable beliefs are invariably vague. To the extent that an instinctive belief is rendered precise, it is open to doubt. "Yet there are beliefs of which such a critical sifting invariably leaves a certain vague residue unaffected" (5.507). Would this vague residue disappear under persevering efforts at precision? It would not" . . . it is not because insufficient pains have been taken to precise the residuum, that it is vague: it is that it is vague intrinsically" (5.508). Peirce gives us an example: the notion of "order in nature." Every formulation of that order in a precise way is open to doubt, and yet for all that, "who can think that there is no order in nature" (5.508)? Such a claim is literally unthinkable since pure chaos cannot be real or be even thought. This residue, then, is indubitable and acritical: indubitable because it is acritical 
and acritical because it is essentially vague. The notion of God is essentially vague; God's reality must be such that it cannot be subsumed under a genus.

According to Peirce, therefore, our notion of God must be anthropomorphic if it is to be capable of belief, and it must be vague if it is to be a notion of God.

\section{The Argument}

The obvious is usually the most difficult thing to grasp and, when grasped, even more difficult to express. For Peirce, God's reality is (and must be) obvious (6.450):

If God really be, and be benign, then, in view of the generally conceded truth that religion, were it but proved, would be a good outweighing all others, we should naturally expect that there would be some Argument for His Reality that should be obvious to all minds, high and low alike, that should earnestly strive to find the truth of the matter; and that this Argument should present its conclusion, not as the production of metaphysical theology, but in a form directly applicable to the conduct of life, and full of nutrition for men's highest growth. (6.457)

Such an argument merits to be called the "Humble Argument." Still, its very simplicity raises problems insofar as reason seeks to analyze and to express the reality in formulas. Augustine of course knew very well what time was until he sought to define it. Peirce's argument presents something of the same impression. But perhaps to be forewarned is to be forearmed. To expect or require an argument couched in the language of "metaphysical theology" is to be disappointed. For one thing, this would be to assume that every argument is an argumentation. For another, Peirce's argument requires a certain kind of activity which leads to a certain kind of experience without which the point of the argument is lost (this does not imply that this activity and this experience are out of the reach of most or even some men). Again, the theoretical justification of the argument, in the sense of showing its reasonableness, depends upon a correct understanding of logic and methodology (6.468). For a certain type of man at least (see 6.486), the force 
and validity of the argument is tied to the correctness of the pragmatic analysis.

The "Humble Argument" is the first step in a complete inquiry concerning God. The other steps are deductive and inductive. This first step results from an "agreeable occupation of the mind" called musement or free meditation (6.458). It is nothing but Pure Play whose only rule is the law of liberty. It is an exercise which has no ulterior purpose, no preconceived notion as to its outcomein short, no prejudices of any kind. In effect, it is the ideal frame of mind for the scientific inquirer because it supposes an openness to entertain and explore every suggestion inspired by the wonders of nature. Musement may take the form of esthetic contemplation, or of free imagining (castle-building), or of considering some wonder in one of the three Universes of Experience, or of wondering at "some connection between two of the three with speculation concerning its cause" (6.458). It is musement in this last form especially from which the Neglected Argument "will in time flower" (6.458).

Peirce was always very hard on "theologians" and "seminary men." He opposed to their mentality that of the "laboratory man" or experimentalist. The latter was the man imbued with the spirit of scientific investigation--an openness to learn the lessons of nature. Such a man does not have his heart set on proving some hypothesis, but rather welcomes disconfirmation of "pet ideas" with as much as or more enthusiasm than he does confirmation. For the laboratory man hypotheses are just that; they are not principles of conduct and they are not objects of belief. In this sense science does not deal with "topics of vital importance."

One who sits down with the purpose of becoming convinced of the truth of religion is plainly not inquiring in scientific singleness of heart, and must always suspect himself of reasoning unfairly. So he can never attain the entirety even of a physicist's belief in electrons, although this is avowedly but provisional. (6.458)

The same remark, of course, applies to one who sits down with the avowed purpose of becoming convinced of the falsity of religion. Peirce's recommendation to practice musement is meant to avoid this sort of false beginning. 
But let religious meditation be allowed to grow up spontaneously out of Pure Play without any breach of continuity, and the Muser will retain the perfect candour proper to Musement. (6.458)

From the nature of the case each one must practice musement for himself. Peirce begins with some advice gathered from personal experience which might help the beginner: the time, the place, the subject matter, and so on (6.459). The one essential, however, whether these particular suggestions prove helpful or not, is to adhere to the law of liberty. He warns that the road to inquiry should not be blocked by prejudice masked as maxims of wisdom (6.460). The course which musement might take, therefore, cannot be prescribed beforehand. Certain kinds of consideration, no doubt, are likely to arise, such as "psychological and semipsychological questions" which in turn will lead to metaphysical and logical ones (6.463-464).

Such meditation might go something like this: (l) consider the "unspeakable variety" of each Universe; (2) consider the "homogeneities of connectedness" within each Universe; and (3) consider the "homogeneities and connections" between two or more Universes (6.464-465). Peirce uses but two brief paragraphs to sketch this threefold consideration. He barely develops each point, for two reasons: first, each must make the meditation for himself in liberty in order to grasp the force of the argument; and, second, justice could not be done to such considerations except by a thorough presentation of synechism and tychism-an impossible task within the scope of the article. ${ }^{4}$ Let us, however, take each of the three points in turn and comment briefly on it.

Point (1): "Variety in the Universes." Peirce maintains that variety, change, and growth are the most immediate, the most striking, and the most pervasive characteristics of our experience. The world of our experience is in constant flux. Now, such a situation in itself does not create any particular expectation concerning the course phenomena are likely to follow or the order that is likely to appear. It can engender only the expectation of further, endless, variety. Where there is no particular expectation concerning the order of events, there can be no surprises, since in such a world anything would be as likely as anything else. Where there are no surprises, there are no questions, and where there are no questions, no expla- 
nations are required. What is surprising in our endlessly varied experience, however, is the fact that there is some order and regularity. It is the law-like character of experience, then, which par excellence needs explaining. Peirce elsewhere developed this line of thought in his polemic against mechanistic determinism. It is not the law-like character of events which "explains" our experience; rather, it is that regularity which must be explained.

Point (2): "Regularity in the Universes." The surprising fact is that amid the flux of experience there are uniformities, not absolute, not exact, but regularities nonetheless. These "laws of nature" are not rigid; they themselves admit of variations ("sporting") and so themselves can change and develop. It is the regularity in experience which renders it intelligible and, Peirce argues, it is regularity which makes the real to be real (since there cannot be an absolutely incognizable). This sort of regularity (less than absolute and exact) is what constitutes reality. This sort of regularity engenders expectation concerning our future experience, allows for surprises, and so is the source of questions.

Point (3): "Regularities between Universes." In the phenomenon of growth all three universes conspire, for "a universal feature of it is provision for later stages in earlier ones" (6.465). Peirce asks whether this might not be accounted for by chance. Can regularity be explained by random interaction? In one sense the answer is yes - in some cases order does in fact arise from random distribution (for example, the action of "conservative forces" in physics). Furthermore, the action of chance is required as at least part of any explanation, since it is order which must be explained. Still, pure chance or absolute randomness cannot be real, since it would be unintelligible. In a word, the action of chance itself has its own law, the "Law of Mind" as Peirce calls it, which is such that, without being absolute and rigid, tends to make it more likely that future activity of an agent will be of a certain sort than some other because the agent has so behaved in the past. ${ }^{5}$ In a word, this peculiar law is the tendency to take habits. Chance or randomness, then, is relative to some expected order. But expected order is based on habit, and habits are not rigidly necessary. In the end, therefore, all processes manifest some degree of regularity, although it may not be the regularity expected. They involve the action of real or objective change (tychism), but also have some, perhaps only "the 
smallest conceivable dose," of the higher element, the Law of Mind (synechism). Absolutely rigid laws of nature as conceived by the mechanistic determinists cannot explain growth and development. In such a world nothing new could ever happen. In fact, law in such a world would be strictly unknowable, since ex hypothesi it would be absolutely determinate, that is, incapable of generalization and therefore incapable of representation by a sign. The law of laws, then, is the Law of Mind, the tendency to take habits (6.102-103, 6.238-268, 6.287-306).

It is this sort of consideration, according to Peirce, which will make the hypothesis of God very attractive. The hypothesis of God as Ens necessarium will itself require that the laws of nature be as synechism describes them, and so if synechism is even approximately correct, the hypothesis has confirmation:

in the Pure Play of Musement the idea of God's reality will be sooner or later to be found an attractive fancy, which the Muser will develop in various ways. The more he ponders it, the more it will find response in every part of his mind, for its beauty, for its supplying an ideal of life, and for its thoroughly satisfactory explanation of his whole threefold environment. (6.465)

So far we have traced how the hypothesis of God might arise through meditation on the order and variety of the real. We have tried to fill in some consideration of Peirce's ontology and cosmology developed over a number of years which are operative in his presentation and which he himself admits the Muser could not critically explore in odd half-hours. Once meditation has suggested the hypothesis, the task of developing its consequences and of investigating its validity and truth remains (6.464).

At this point a trained mind will demand that an examination be made of the truth of the interpretation; and the first step in such an examination must be a logical analysis of the theory. But strict examination would be a task a little too serious for the Musement of hour fractions, and if it is postponed there will be ample remuneration even in the suggestions that there is no time to examine; especially since a few of them will appeal to reason as all but certain. (6.464) 
Peirce now explores some of the peculiarities of the Godhypothesis and some of its consequences. After that there is a consideration of its logicality. Let us follow his order.

\section{THE HYPOTHESIS}

According to the pragmatic maxim, the entire meaning of any conception is constituted by the conceivable practical effects it would have upon our future conduct (5.402). Peirce appeals to this principle in analyzing the God-hypothesis. Its meaning is its conceivable effects upon our conduct, and its truth is confirmed insofar as it has power to make men strive to regulate their conduct according to those consequences. Yet the hypothesis is a "peculiar one" (6.466) not only because of its extreme vagueness, but also because "it supposes an infinitely incomprehensible object, although every hypothesis, as such, supposes its object to be truly conceived in the hypothesis" (6.466). As we have seen, every proposition (hence, every hypothesis) is to some degree vague. Hypotheses can be judged true or false only to the extent that they are made definite. Black, for example, maintains that all terms which require for their application the recognition of the presence of sense qualities are vague. ${ }^{6}$ There are no rules for "drawing the line" between cases that fit the description and those that do not. Still, in order to reason with "loose concepts," some decision procedure must be adopted. Black suggests one for empirical concepts. But what about concepts like "order of nature" or "God"? If we are truly to conceive of an infinitely incomprehensible object, then according to Peirce our conception must be "vague yet . . . true so far as it is definite, and as continually tending to define itself more and more and without limit" (6.466).

To approach this logical problem we must return to the notion of vagueness. Concepts can be vague with respect to logical breadth or logical depth. Vagueness in logical breadth means that there are individuals about which there would be disagreement as to whether they belong to the class or not. Thus, the class "chair" (to use Black's example) is vague in logical breadth because, although we can define the concept well enough not to confuse it with another (say that of "table"), and there are individuals that 
indisputably belong to the class, there are others that are "borderline" cases. Vagueness in logical depth means vagueness with respect to the notes that define the class. It is not so much that there are borderline cases as that we cannot say just what the defining characteristics are-not because of ignorance, but because what we are trying to define resists classification. ${ }^{7}$ In such a case we can better say what the concept does not mean, and still what is intended is not something merely negative. Such vagueness in logical depth may not necessarily mean that there is any doubt as to which individuals are meant. The transcendentals-being, unity, truth, goodness-have this sort of vagueness. It would be begging the question to say that therefore these notions are meaningless. The notion of God has vagueness in logical depth.

How can such a notion be rendered definite enough to be capable of a true or false judgment? Since no sign is absolutely determinate, the sign "God" can be made definite only by rendering it general. But all such attempts fail in one way or another since what is intended by "God" is not the sort of thing that can be in a class. It would seem, then, that all claims about God must be neither true nor false because of their irremediable vagueness. Yet this will not do either, because we do in fact discriminate between predicates applicable to God and those that are not. This is independent of whether we admit God's reality or not. It might be claimed that all predicates applied to God are inappropriate precisely because the notion has no meaning. The same would apply to all "metaphysical" claims. The inconvenience, of course, as has been pointed out numberless times, is that this claim itself is "metaphysical." Again, one might wish to exclude the notion of God on metaphysical grounds. In that case, either one is claiming that the statement "God is real" is false (and so admitting it has meaning) or one is claiming meaninglessness for the concept on grounds other than its vagueness.

It is impossible here to enter into all the problems raised by "God-talk." Perhaps in the end one will be forced to some version of the ancient via negativa, via affirmativa, and via eminentiae. In such a case, the reality intended would be said to show itself in the very failure of every attempt adequately to express it. Such a disclosure ${ }^{8}$ would be different from the disclosure that something is without meaning at all, since in that case one would see either 
that the expression is syntactically incorrect or that it contains a contradiction, logical or performatory. But is this the case with "God" and the "transcendentals"? Perhaps we simply have to face the paradox of admitting a type which cannot be a type at all. Peirce struggles with this sort of puzzle but does not come to any clear resolution. He says, for example, that to think of God as having a purpose is less false than the opposite (6.466). It seems that he is getting at the paradox we just mentioned, although he does not state it in so many words. Peirce seems to mean that from the supposition that God has purpose we can draw true conclusions about the Universes of Experience (for example, that they are in continual process of development), while from the opposite we can draw no conclusion at all. This would make the former supposition preferable, and so while not exactly true of God (since God's having a purpose does not entail change in God, while ours does), still it is "less false" in its consequences.

Conceiving God as purposeful poses another puzzle for Peirce. He argues that if the hypothesis of God is subject to growth in that it tends to define itself without limit, it must represent God as subject to growth too. But the representation of God as "growing" is "contradicted in the hypothesis from its very first phrase," and yet since this cannot be eradicated from the hypothesis it "cannot . . . be flatly false" (6.466). There must be something like growth in God's reality although we have no precise idea what it is like. This follows from Peirce's understandings of Thirdness as the category of the real-and Thirdness involves mediation and continuity. The real and the intelligible are identical, and both are thirds. God, then, must be conceived after the analogy of Mind (6.502).

It may be that what leads Peirce into this sort of difficulty is the extreme version of realism which he espoused. He seems to think that whatever characterizes the representation of some reality must also characterize what is represented. This thesis is open to doubt, and many philosophers would flatly deny it. One might want to distinguish the proper and proportional object of finite intelligence from a transcendent and disproportionate object which must be represented to finite intelligence in a discursive way even if the object itself is not subject to such limitation. There is something of this idea in the attempt to understand continuity (a subject dear to Peirce), in that continuity must be represented conceptually 
through the use of discreteness-a series is continuous if between any two members of the series there is always another. Such a representation always carries a clause (explicit or implicit) negating what in the representation is subject to limitation. This supposes of course some theory of limitation such as the Scholastic development of act and potency. Peirce does have a theory of limitation of a sort. The category of Secondness is meant to account for it, and, as we have seen, this is the category of existence. This was the reason why God could not properly be said to exist. Still, we cannot have an experience of anything not related to existents in some way, since our experience is constituted by all three categories. The categories cannot be experienced in isolation but can only be distinguished within experience through "precission" or abstraction $(1.353,1.549) .{ }^{9}$ This would require Peirce to say that we have no experience of God immediately but only in and through the world of intelligible actuals. This would be direct but mediated knowledge. Again, we have seen that Peirce contends that we know God by direct experience.

According to Peirce, therefore, it is "less false" to speak of God as having a purpose than as being purposeless. It cannot be simply true because "a purpose essentially involves growth and so cannot be attributed to God" (6.466; emphasis added). Whether it does essentially involve growth is the question. ${ }^{10}$ It may be the case that for us to have a purpose in fact always has concomitant with it growth of some sort. But might not this be only accidental? Could it be, for example, that having a purpose might look only to the development of something else? It might be that to accomplish the purpose with respect to the other, the purposer might have to act and in acting himself develop by reducing his potentialities to act. But is this essential to having a purpose? To put the same thing in another way: is it essential to the notion of actively accomplishing something that the agent undergo change? Is it conceivable that only the patient change? Is not this just what we would expect of an infinite agent? Insofar as we have a purpose we undergo change, but this may be due not to our having a purpose but to the fact that we do not have actually infinite power. Then it would follow that God cannot be said to have a purpose in just the same way as we do, but that He has something like a purpose in that what $\mathrm{He}$ intends in His creative act is accomplished in the creatures-that 
is, they come to be and develop according to His will. Peirce seems in fact to be getting at this notion since he tells us that the implications of thinking of God as "growing" (having a purpose) will be maintained insofar as it concerns the Universes, "while its implications concerning God will be partly disavowed" (6.466). Still, with respect to God these implications will be "held to be less false than their denial would be" since that denial would lead us to think of God as purposeless.

\section{Justification AND VAlidity}

The logical justification of the God-hypothesis would require: (1) an examination of the elements of any complete inquiry; (2) a discussion of the logical validity of each element; and (3) an appraisal of the place of the Neglected Argument in this process. Peirce merely summarizes items (l) and (2). They are treated copiously in his other logical writings. Item (3), however, receives special attention.

The validity of deduction and induction need not detain us. What is important is the justification of retroduction since the first stage of the Neglected Argument is of that form. Every real advance in knowledge comes through retroduction. "Neither deduction nor induction contributes the smallest positive items to the final conclusion of the inquiry" (6.475). Deduction merely draws out explicitly what the hypothesis contains. Induction seeks to evaluate its truth in terms of experience. It is retroduction which supplies the major premise for the deduction and tells the inquirer what to look for in applying inductive techniques. Retroduction is the light of intelligence itself, "il lume naturale," and, according to Peirce, it testifies to the affinity of mind and nature. The conjectures it produces are the spontaneous offshoots of instinctive reason.

It is the notion of instinctive reason that Peirce finds to be at the base of retroduction as an argument form. The spontaneous and overpowering impulse to form hypotheses is a "symptom of its being instinctive" (6.476). This is, in general, the natural disposition of intelligence. 
To give the lie to his own consciousness of divining the reasons of phenomena would be as silly in a man as it would be in a fledgling bird to refuse to thrust its wings and leave the nest, because the poor little thing has read Babinet, and judged aerostation to be impossible on hydrodynamical grounds. (6.476)

The real question is whether men in fact have this ability to discern in particular cases which among alternative hypotheses is "instinctive." Peirce gives an affirmative answer:

Not, I reply to the extent of guessing right the first time, nor perhaps the second; but that the well-prepared mind has wonderfully soon guessed each secret of nature is historical truth. (6.476)

Following scientific procedure, man has "wonderfully soon" guessed correctly among the infinitely many possible hypotheses which might explain perplexing phenomena. The implication is that the correct method itself is a matter of instinct. This does not mean that every analysis of method is correct, but only that the actual use of the method is instinctive and that if the method be persevered in, it is self-corrective even with respect to formulating it properly.

But perhaps this "guessing right" in a relatively few tries is mere coincidence and not due to the instinct of reason? Peirce's answer is twofold: (l) the probability of this being mere chance is so small "that it would be ridiculous to suppose our science so to have come to pass" (6.476); and (2) even granting the element of chance as an "explanation" of any purposed human action, this still leaves unaccounted the role played by reason in that action, or else it must suppose that reason has nothing to do with it at all (6.476). Peirce concludes:

There is a reason, an interpretation, a logic, in the course of scientific advance, and this indisputably proves to him who has perceptions of rational or significant relations, that man's mind must have been attuned to the truth of things in order to discover what he has discovered. It is the bedrock of logical truth. (6.476)

This "bedrock of truth" was called by Galileo "il lume naturale," and the heuristic principle that it dictates is to prefer the simpler of two hypotheses. But simpler does not necessarily mean logically simpler. It is to be understood as referring to the "more facile and 
natural" hypothesis-the one instinct suggests. As we have seen, a symptom of the instinctive nature of an hypothesis is its initial compulsive force, but this has to be put to the test and controlled by the techniques of scientific method.

It was not until long experience forced me to realize that subsequent discoveries were every time showing I had been wrong (i.e., in supposing that "simpler" meant "logically simpler"), while those who understood the maxim as Galileo had done, early unlocked the secret ... that it is the simpler Hypothesis in the sense of the more facile and natural, the one that instinct suggests, that must be preferred; for the reason that, unless man have a natural bent in accordance with nature's, he has no chance of understanding nature at all. . . . I do not mean that logical simplicity is a consideration of no value at all, but only that its value is badly secondary to that of simplicity in the other sense. (6.477)

\section{APPliCATION to THE NEgleCted ARguMENT}

Peirce imagines three sorts of men and their reactions to his argument:

the first, of small instruction with corresponding natural breadth, intimately acquainted with the N.S., but to whom logic is all Greek; the second, inflated with current notions of logic, but prodigiously informed about the N.S.; the third, a trained man of science who, in the modern spirit, has added to his specialty an exact theoretical and practical study of reasoning and the elements of thought, so that psychologists account him a sort of psychologist, and mathematicians a sort of mathematician. (6.478)

No space is given to the reaction of the second type of man, because "the current notions of logic" are full of errors. Even though such a man were well-informed about the argument, he would not be able to understand it, much less criticize it. The first type, however, is naturally well-disposed to grasp the argument and to accept it, because he follows his instincts in the matter without the complications suggested by critical reflection. Such a man would have learned that "nothing has any kind of value in itself . . . but only in its place in the whole production to which it appertains" (6.479). Thus, he is disposed to think of God as having a purpose. He will 
perceive evil as leading ultimately to good in that the fight against it is required by the cosmic law of growth. Thus

he may hope that it (evil) be best for them (his dear ones who suffer evil), and will tell himself that in any case the secret design of God will be perfect through their agony; and even while still hot from the battle, will submit with adoration to His Holy Will. He will not worry because the Universes were not constructed to suit the scheme of some silly scold. (6.479)

Thus, this man will "shape the whole conduct of his life and all the springs of action into conformity with that hypothesis" (6.466). This is Belief.

The third type of man, while well-disposed to entertain the hypothesis because he feels its initial attraction, still because of his training requires that it be put to the test:

the third man, considering the complex process of self-control, will see that the hypothesis, irresistible though it be the first intention, yet needs Probation; and that though an infinite being is not tied down to any consistency, yet man, like any other animal, is gifted with power of understanding sufficient for the conduct of life. (6.480)

The test to which the hypothesis must be put, therefore, "must lie in its value in the self-controlled growth of man's conduct of life" (6.480). This man requires critical reflection upon the dictates of "common sense" and also "instinct" to see whether they are authentic. If they are, they will survive, since in the end what is real will out. Intelligence is nothing but the natural disposition to learn the lessons of experience. The third man, therefore, has come to know that the first and basic principle of "common sense" and of "instinct" is identical with correct scientific procedure. Pragmatism, according to Peirce, is the proper analysis of such procedure. It is, then, in accord with instinct and indeed is called "Critical Common-sensism."

This brings him, for the testing of the hypothesis, to taking his stand upon Pragmaticism, which implies faith in common sense and in instinct, though only as they issue from the cupel furnace of measured criticism. (6.480)

The hypothesis of God is to be explored for its implications concerning human conduct. Those implications are to be considered 
according to the requirements of proper thinking, acting and feeling explored in the normative sciences: logic, ethics, and esthetics. As speculative sciences these three do not set down particular practical imperatives but only the general requirements for anything to be true, good, or beautiful. ${ }^{11}$ The hypothesis of God is tested in its ability to render practical and operative what those sciences only generally and formally characterize.

A man of the third type, then, might reason as follows: since there is a strong, initial impulse to believe some proposition (say, that God is real, or that there is order in nature, or that incest is wrong), there is a strong presumption in its favor. This presumption is further strengthened if history shows that such belief has been held by most men over long periods of time. Consequently, it would be unreasonable not to take such beliefs seriously or to abandon them simply for theoretical reasons (recall the example of the fledgling bird). It would be unwise to begin to practice incest because one has theoretical difficulties in establishing its immorality. It would be irrational to abandon entirely the notion of order in nature simply because all such precise statements of that order are open to doubt. It would be unreasonable to reject belief in God simply because the hypothesis is essentially vague, and it would be unreasonable to suspend indefinitely such belief on the grounds that there is no apodictic argument in its favor. All these conclusions have a theoretical justification in terms of a proper understanding of human inquiry. If all knowledge comes through experience, then experience is the great teacher. If these beliefs are in fact false, experience will sooner or later find it out since induction is self-correcting. To take the God-hypothesis: if it arises spontaneously in musement as highly plausible, if it unifies otherwise fragmentary experiences, and if its consequences for human conduct are to impel men to conform their lives to the ideals it offers (described in a formal way in Normative Science), then reason requires that the hypothesis be approved not only theoretically but also practically - that it be believed. In such a case reflection confirms impulse. The desire to conform action to belief and to control belief through critical reflection is the drive of intelligence itself. The outcome is reasonable belief. 


\section{Summary: A Nest of Arguments}

In an "Additament" at the end of his argument, Peirce sums up the results. The Neglected Argument is really a nest of three separate but related arguments. The first and innermost of the nest is the Humble Argument properly so called. It is humble because "it is just as good an argument, if not better, in the form it takes in the mind of the clodhopper" (6.483). It is the argument which has the most religious force since it is nothing but "the honest, sincere and unaffected, because unprepense, meditation upon the Idea of God" (6.486). The pure play of musement shows the Idea itself to be so admirable and wonderful as to be worthy of adoration. It is this movement of the spirit which tends to produce a truly religious belief in God's reality and nearness. This argument is reasonable because it arises naturally and results in the Muser's determining to shape his conduct in accord with the Idea.

The second argument of the nest is the Neglected Argument properly so called. It consists in showing that the Humble Argument is indeed the natural fruit of free meditation and that the Idea is so beautiful and awesome as to be adorable. In a word, it tries to show that the Idea of God, far from being vicious or superstitious, is instinctive. This is done by showing that the Idea is the natural outcome of meditation upon the three Universes of Experience, especially from the point of view of their origin. Peirce sees this moment as an apology for the Humble Argument. The Humble Argument is a lived process which one has to experience for oneself in order to feel its force (6.435-439). It is, therefore, strictly speaking, an argument and not an argumentation. Its formulation and defense in the Neglected Argument involves argumentation.

The third argument of the nest is a further development of the Neglected Argument and completes the vindication of the Humble Argument for the man trained in science and familiar with logic. It is based upon careful study of scientific method. Once such an analysis has been made, one compares the process of thought of the Muser as he reflects upon the Universes of Experience with the process of thought employed in scientific discovery. One finds that the Humble Argument is nothing but the first stage of such 
discovery-the formulation of an hypothesis through observations and reflection. The hypothesis so formed, however, differs from ordinary scientific hypotheses in three ways: (l) it has an extraordinary degree of plausibility (so much so that those not used to critical reflection will be tempted to give up any further investigation in the belief that the hypothesis is fully justified); (2) the hypothesis is very vague, so that all attempts at precision render the hypothesis less satisfying, indeed open to doubt with respect to that precision, and yet an indubitable residue remains after each such attempt (recall the example of "order in the universe"); (3) the hypothesis has continuing influence on human conduct. It is in terms of this last characteristic that the scientific man must continue to investigate the hypothesis beyond its initial attractiveness. He must put it to the "pragmatist's" test. If the hypothesis is seen to have powerful consequences in shaping human conduct in the good, then according to Pierce it is a reasonable object of belief. In terms of its truth, it is seen to be "less false" than its opposite, to use his own unusual expression.

Intelligence is a natural capacity (an instinct) for discovering the "secrets of nature" (see 6.414-418, 6.499). Intelligence supposes the intelligible. The intelligible and the real must be co-extensive since otherwise there would be the unknowable thing-in-itself. If the real were only partially intelligible, something would be real which was not only not known but could not in principle be known. Such an hypothesis would be to give as an explanation not merely the inexplicable but also the unintelligible. Such a view of explanation cannot be formulated without giving the lie to itself. There is, then, an "affinity" between intelligence and the real. Peirce calls "God" that reality which is the source and origin of this integration-of the intelligibility of phenomena. The notion remains vague but true insofar as it can be made definite; it is strictly indubitable insofar as it remains vague. The difficulties in attempting to render the notion definite are many, and insofar as generalizations serve in the attempt, those are acceptable which are less false than their opposites. It is less false to say of God, therefore, that $\mathrm{He}$ has purpose than to say that $\mathrm{He}$ is purposeless, because the first allows us to deduce the world's intelligibility (already known as a fact from the nature of inquiry itself) and to 
conform our conduct to the highest ideal of love, while the other does not.

Knowledge of God, like all human knowledge, is based upon direct experience, even though God is not experienced as an object among other objects. God must remain vague and mysterious. God is encountered rather than deduced, and this encounter takes place along with and within experience of the world of space and time. As so encountered, $\mathrm{He}$ is recognized as not confined to the spatiotemporal conditions of our experience of objects. Though God is not grasped as a result of reasoning, reasoning can help us recognize God in the encounter (6.493). Thus, Peirce argues that those theologians who hold exclusively to negative theology to the exclusion of any positive content have made a mistake. We can have some positive idea of God through the world of experience which insofar as it is intelligible is nothing but His Thought.

Of course, various great theologians explain that one cannot attribute "reason" to God, nor perception ... and, in short, that his "mind" is necessarily so unlike ours, that some-though wronglyhigh in the church say that it is only negatively, as being entirely different from everything else, that we can attach any meaning to the Name. This is not so; because the discoveries of science, their enabling us to predict what will be the course of nature, is proof conclusive that, though we cannot think any thought of God's, we can catch a fragment of his thought, as it were. (6.502)

\section{Notes}

1. Peirce's article "A Neglected Argument for the Reality of God" first appeared in the Hibbert Journal, 7 (1908), 90-112, and is included in the Collected Papers, 6.452-91. The discussion will concern this article.

2. James's remark (in Pragmatism, p. 5) was made concerning Peirce's lectures on Pragmatism given at Harvard in 1903. See editor's note, Collected Papers V, p. 11.

3. I have developed these ideas in another essay, "Vaguely Like a Man': The Theism of Charles S. Peirce"; see chap. 11, above.

4. For a detailed exposition of Peirce's synechism and tychism see my Charles S. Peirce: On Norms and Ideals (Amherst: University of Massachusetts Press, 1967), parts 2 and 3.

5. See Peirce's essay, “The Law of Mind” (6.102-163). 
6. "Vagueness: An Exercise in Logical Analysis," Language and Philosophy (Ithaca: Cornell University Press, 1949), pp. 25-58.

7. Vagueness in depth is not to be confused with ambiguity as defined, for example, by Black (ibid., p. 42n33). According to him, ambiguity "is constituted by inability to decide between a finite number of alternative meanings having the same phonetic form (homonyms)," Ambiguity can be removed; vagueness in depth cannot be in all cases.

8. See W. de Pater, Linguistic Analysis and Theology (Louvain: Acco, 1970); Taagalanalytische perspektieven op godsdienst en kunst (Antwerp: Nederlandsche Boekhandle, 1970); Theologische Sprachlogik (Munich: Lösel-Verlag, 1971).

9. For a further discussion of the categories and their interrelation see my Norms and Ideals, part 1, chap. 1.

10. In 6.502 Peirce explicitly says that "it is impossible to say that any human attribute is literally applicable" to God.

11. See 5.14-40, and my Norms and Ideals, for an exposition of normative science. 